\title{
On some strange birds from the islands of Komodo and Rintja between Sumbawa and Flores (Lesser Sunda Islands)
}

\section{A. Hoogerwerf*}

During our 1953-expedition to the islands of Komodo, Padar and Rintja, the home of the Giant Lizard Varanus komodoensis, a small collection of birds was collected among which are some specimens which do not fit into the material of the species known from the surrounding islands. They were studied within a year after the date they were obtained.

Because the availability of more material seems important these notes are published in order to encourage future collectors, who might have an opportunity to visit the islands.

\section{Accipiter novaehollandiae (Gmelin)}

On account of the particulars derived from literature about the differences between the "Rassenkreise" fasciatus and novaehollandiae it became evident that the three birds of prey secured by me on Rintja Island which is very close to the island of Komodo, belong to the latter species, certainly not to fasciatus. Though the original diagnosis of the subspecies sylvestris (Wallace ${ }^{10}$ ) can be used rather well for the Rintja skins, this seems not sufficient to decide whether they indeed belong to this race. Also some other particulars compiled from literature did not suffice to conclude nor does the (rather scanty) material of novaehollandiae present in the Bogor Museum, consisting of two adults and one juvenile of the subspecies sylvestris, originating from Sumbawa and Flores. They all differ very distinctly from those Rintja birds, as does some material available in the Leiden Museum. The rather doubtful subspecies sumbaensis was not taken in consideration, because Stresemann ${ }^{8)}$ and Mayr ${ }^{1)}$ made it clear that the only specimen hitherto known of this race may be a hiogaster which was wrongly labelled, so that in accordance with Mayr no representatives of Accipiter novaehollandiae are known from the island of Sumba.

When comparing the two Rintja skins of adult birds with both old sylvestris just mentioned, the differences are striking. The vinaceous tinge on the under surface is much darker in the Rintja material and the underlying tint lighter, causing much more contrast; the abdominal region and undertail-coverts too are more intensively barred. The tibial feathering is very dark, making the bars indistinct; the markings on the innerwing are darker too, causing very distinct bars on the wing-quills as is

\footnotetext{
* P. C. Hooftstraat 8, Bakkum NH, Holland.
} 


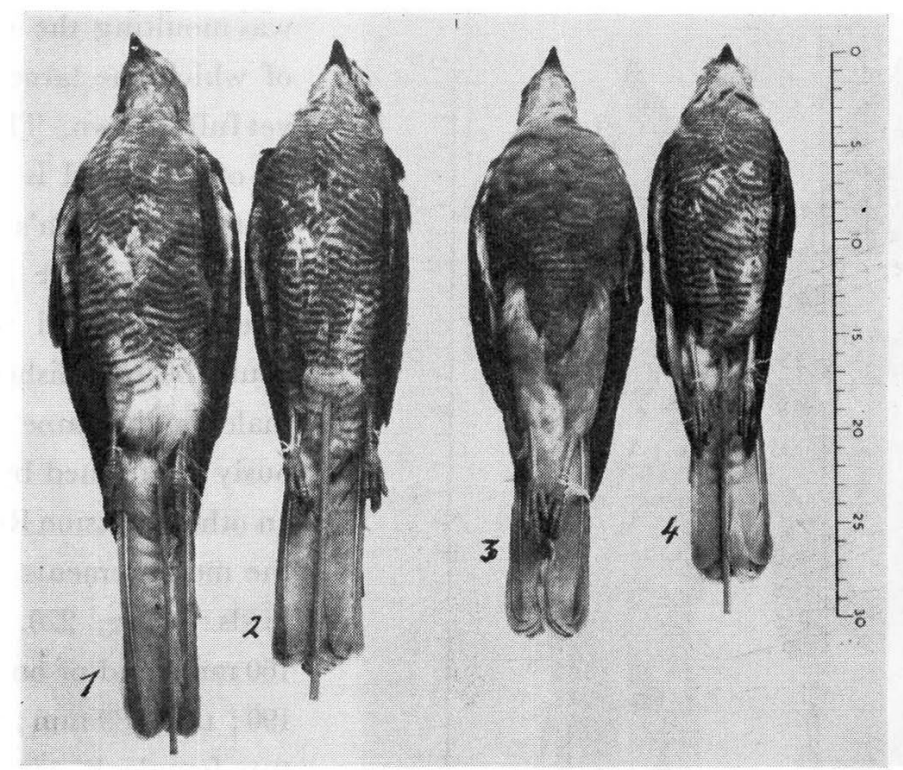

Fig. 1. Accipiter novaehollandiae subspp. (adults)

1. Female from Komodo Island

2. Male from Komodo Island

3. Female subsp. sylvestris from Sumbawa

4. Male subsp. sylvestris from Flores

(More contrasty underparts, more distinctly banded tail in Komodo birds)

the case on the tail, most conspicuously on the undertail. Though wings and upper parts are darker grey than in sylvestris of old date it seems not justifiable to attach much value to this feature because it might be the consequence of post mortem alterations.

The colour differences as indicated above are present in both sexes and the Rintja material is very uniform on all those points. There is some variation in both old skins of sylvestris, for the male from the island of Flores is less distinctly barred on the under surface than is the female of Sumbawa though the vinaceous tone on those parts does not differ much in both these birds.

The juvenile from Rintja too differs from a Similar bird originating from Sumbawa; in the first place the markings on the underparts are finer and more numerous in the Rintja specimen and the colour is darker and less brown. Moreover the dark bars on the tail and wing-quills and also on the wing-coverts are darker and more numerous, especially on the undertail.

In size the Rintja adults do not differ much from the old material but they average a trifle smaller in the measurements of wing, tail and culmen. The difference in wingsize may be more important because of the fact that the male bird from Flores 


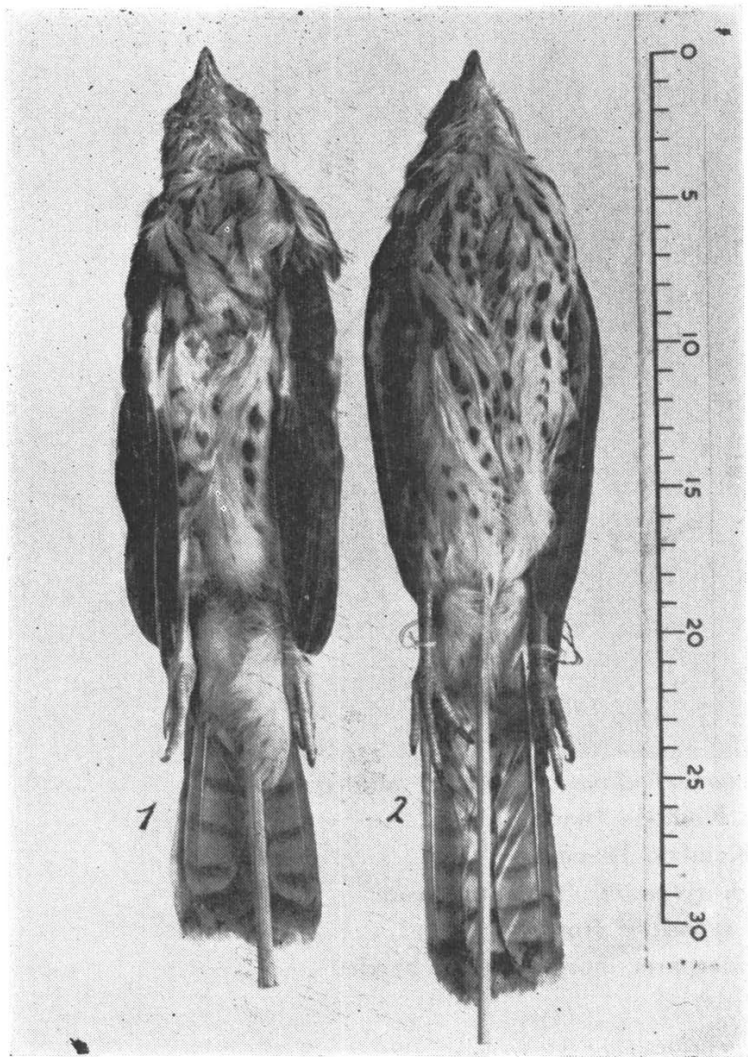

Fig. 2. Accipiter novaehollandiae subspp. (juvenile females)

1. Subsp. sylvestris (Sumbawa)

2. Komodo bird

(Markings on under surface finer and undertail more intensively banded in Komodo bird) was moulting the wing-primaries of which the largest ones are not yet fully grown. The third primary of that bird is $10 \mathrm{~mm}$. longer than in Rintja's male which points to a more important difference in total wingsize than could be established now. This male is the same bird as previously mentioned by Rensch. ${ }^{6}$ ) At an other occasion Rensch ${ }^{\text {) }}$ gave as the measurements of two female birds: wing, 220, 221; tail, 161, $160 \mathrm{~mm}$. and of one male: wing, 190 ; tail, $139 \mathrm{~mm}$; for two immature females he mentioned : wing, 212, 203; tail, 161, $162 \mathrm{~mm}$, which are larger than those found by me, so far as the wingsize is concerned.

Wallace, ${ }^{10}$ ) however, found for the winglength of sylvestris 175 ( $\hat{\delta}), 200$ (o) and for the length of the tail $137.50(\hat{\delta})$ and $156.25 \mathrm{~mm}$ (우), measurements which are smaller than mine for the Rintja material, so that there is perhaps not much difference in size between the latter population and true sylvestris. Also some measurements taken by Junge on material present in the Leiden Museum, point to such a direction, for he gave 178 ( $\delta$ ) and $204 \mathrm{~mm}$ ( $($ ) for the wing and $133(\hat{b})$ and $162(ㅇ) \mathrm{mm}$ for the tail in two birds examined by him.

Prof. Stresemann was so kind to compare the Rintja material with an adult female bird from Flores and an adult male and juvenile female from Sumbawa, present in the collections of the Berlin Museum; as a result of his examination he found that both adults from Rintja indeed show darker bars below and have darker upper parts. But he thinks it not very probable that on the small island of Rintja should live an other subspecies of this bird of prey than is known from the islands of Flores and Sumbawa.

Dr. Amadon kindly compared the Rintja birds with four adult females and an 
immature bird of sylvestris present in New York's Museum of Natural History. Three of his female birds were a trifle lighter ventrally than the Rintja female but the fourth was almost a match and the immature specimen from Rintja was found very like the one from Flores he disposed of. He considered this a somewhat dubious case, difficult to be solved without more material.

The three birds discussed above have the Bogor Museum no's : 22.585/7.

Measurements (in mm.) of the subspecies sylvestris:

令 f Wing; Rintja : 179; Flores : 184; Flores (Leiden Museum, measured by Junge) : 178.

Tail; Rintja: 138; Flores: 142; Flores (Leiden Museum): 133.

Culmen; Rintja: length from border of cere: 14.5; depth from border of cere: 10.7; Flores: 14.9 and 10.7; Flores (Leiden Museum): 15.

우 우 Wing; Rintja: 203; juv.: 196; Sumbawa: 211; juv. 181; Flores (Leiden Museum): juv. 204.

Tail ; Rintja : 164 ; juv. : 157 ; Sumbawa : 168 ; juv. : 127; Flores (Leiden Museum) : juv. 162 .

Culmen ; Rintja : length from border of cere : 16 ; depth from border of cere : 12 ; juv. : 15.9 and 11.8; Sumbawa : 17.2 and 12.5 ; juv.: 15.5 and 10 ; Flores (Leiden Museum): juv. 14 .

\section{Coracina novaehollandiae (Gmelin)}

The three male and three female birds belonging to the subspecies floris and originating from Flores and Sumbawa which are present in the Bogor Museum do not show considerable individual variations, but they do differ somewhat in the quantity of white on the abdominal region, whereas some skins are purer grey below than others. This is the case in a male secured on Sumbawa in 1927 and in the only female bird we obtained on Komodo Island in 1953, which makes it almost impossible to separate both these specimens because of their pure grey underparts leaving out of account, of course, the sexual dimorphism in the plumage. The Komodo bird, however, is still a trifle lighter on the abdomen and undertail-coverts than all other six individuals.

On the upper surface too there is some individual variability in the tinge of the grey and in the extension of the light edges to the wing-quills, which are most strikingly present in the Sumbawa male, discussed above and in two females secured on Flores in 1927.

The female bird from Komodo is a trifle darker on the wings and upper parts than the old material but that might be caused by the difference in collecting period. There is also some difference in the extension of the white on the innerwing between this Komodo specimen and the other skins, but it is apparently not justifiable to attach more significance to this difference than an individual one as is the case with 


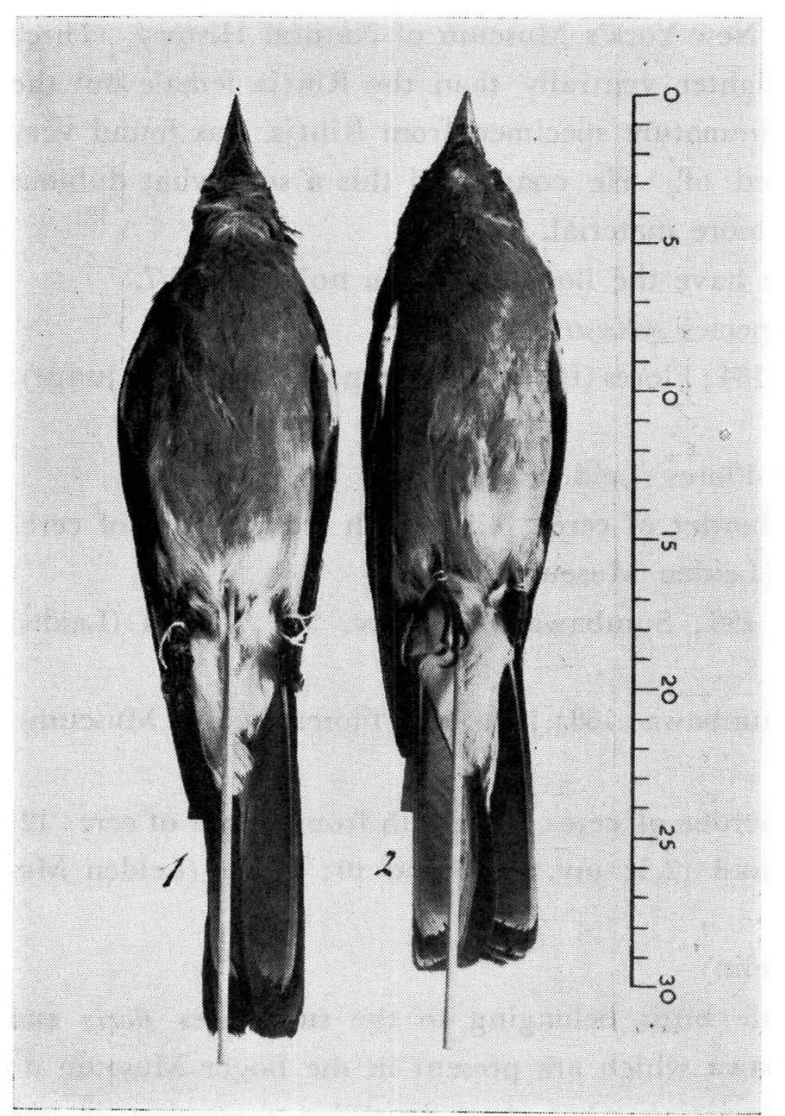

Fig. 3. Coracina novaehollandiae

1. Coracina novaehollandiae from Komodo Island (우)

2. Coracina uovaehollandiae floris from Sumbawa (우)

(Strong bill and long tail of Komodo bird are very conspicuous)

male bird in the Leiden Museum measured by Junge showed a wing of 160, a tail of 134 and a culmen of $24 \mathrm{~mm}$. Also three other birds in the Leiden Museum, seen by me, differ in the same respects as do the Bogor specimens and Rensch' material: they are much smaller which is even obvious without taking measurements.

Because of its large size the Komodo female shows more resemblance to the subspecies sumbensis known from the island of Sumba, but birds of this race differ considerably in plumage making it impossible to unite the Komodo bird with them.

I did not compare the bird discussed above with the subspecies alfrediana, personata and lettiensis, known from the Lesser Sunda and Southwestern Islands, but I suppose that, for zoogeographical reasons, the Komodo bird cannot be identical with one of these races. 
Dr. Dean Amadon was so kind to compare the Komodo female with four skins of alfrediana originating from Alor, present in New York and found it different and Prof. Stresemann supposed this specimen to be nothing more than an extremely large individual of the nominate race.

Peters $^{5}$ mentions still another subspecies which should winter on the Lesser Sunda Islands, viz. subpallida, but according to $\mathrm{Mees}^{4}$ ) neither Keast nor he found a specimen of this race outside its accepted breeding range which should be confined to the northwestern part of Australia; this strongly points to the population being largely sedentary!

On account of the large measurements mentioned by Mees (loc. cit.) for a female bird of this form, the Komodo bird cannot belong to it; there is perhaps also quite an important difference in plumage when looking upon the particulars as published by the latter author. In contradistinction to Peters, Mees writes that it is custom to call those Australian migrants didima, thus identifying them with populations from northern, tropical Australia. This again is considered very unlikely by Mees because such migrants would be expected to belong to the southern-most populations of the species (Tasmania, southern Australia), but never to the northern, tropical populations.

There are indications that Coracina novaehollandiae may be considered a migrant to southern New Guinea as indicated by Mayr ${ }^{2}$ ) because representatives of the species of which the racial affinity is not yet known to me, were observed rather plentifully by me during the dry season in the neighbourhood of Merauke and almost never in the rainy period. This, of course, does not exclude the possibility that the species breeds in certain parts of south New Guinea as is evident from the fact that, according to Mees, adults have been observed attending fledglings near Port Moresby far east of Merauke.

Without loosing ourselves in speculations about the real affinity of those migrating representatives of the species, I like to emphasize that there might be quite a number of reasons inducing birds to leave their breeding ranges even in tropical regions. It therefore seems to me not justifiable to exclude the migration of certain species from northern Australia to south New Guinea because of the fact both these areas are tropical. After my rather long field-experience in the latter part of the world I am quite convinced that bird-migration from north Australia to New Guinea is effectuated on a much larger scale than hitherto known; maybe in such cases migration is not the right conception but that is not important in this case.

Measurements (in $\mathrm{mm}$.) inclusive those compiled from literature:

ô ô Wing ; floris (Sumbawa, Flores): 168, 169, 171; floris measured by Rensch')): 164, 167, 170, 170, 170, 172, 173, 176.

Tail ; floris (Sumbawa, Flores): 133, 138, 141 ; floris (Rensch): 121, 126, 129, 130, 133, 133, 135, 136, 138. 
Culmen ; floris (Sumbawa, Flores) : 23.9, 24.2, 26 ; floris (Rensch) : 22.5, 23, 23.5, 24, 24, 24, 25, 25, 26.

Max., min. and average measurements :

floris Sumbawa, Flores floris (measured by Rensch)

$\begin{array}{lcc}\text { Wing: } & \frac{168-171}{169.33} & \frac{164-176}{170.25} \\ \text { Tail : } & \frac{133-141}{137.33} & \frac{121-138}{131.22} \\ \text { Culmen : } & \frac{23.9-26}{24.70} & \frac{22.5-26}{24.11}\end{array}$

우 우 Wing; floris (Sumbawa, Flores): 168, 170, 172 ; floris (measured by Rensch): 164, 166, 167, 167, 168, 169, 169 ; fioris? (Komodo): 181.50; sumbensis (Sumba) : 177.

Tail ; floris (Sumbawa, Flores): 133, 137, 140 ; fioris (Rensch): 121, 121, 123, 128, 128, 129 ; floris? (Komodo): 155 ; sumbensis (Sumba): 152.

Culmen ; floris (Sumbawa, Flores): 22.1, 22.1, 22.2 ; floris (Rensch): 22, 23, 23.5, 24, 24, 24.5, 25; floris? (Komodo): 24.60; sumbensis (Sumba): 25.

Max., min. and average measurements :

$\begin{array}{lcccc} & \begin{array}{c}\text { floris } \\ \text { Sumbawa, Flores }\end{array} & \begin{array}{c}\text { floris } \\ \text { (measured by Rensch) }\end{array} & \begin{array}{c}\text { floris? } \\ \text { Komodo }\end{array} & \begin{array}{c}\text { sumbensis } \\ \text { Sumba }\end{array} \\ \text { Wing: } & \frac{168-172}{170} & \frac{164-169}{167.14} & 181.50 & 177 \\ \text { Tail : } & \frac{133-140}{136.67} & \frac{121-129}{125} & 155 & 152 \\ \text { Culmen : } & \frac{22.1-22.2}{22.13} & \frac{22-25}{23.71} & 24.60 & 25\end{array}$

\section{Philemon buceroides}

Rensch $^{6}$ separated birds from Sumba (sumbanus) on account of their large size when compared with representatives of the nominate race, known from Timor, of neglectus (Lombok, Flores) and of plesseni (Southwestern Islands) and because of the shorter lower mandible and darker plumage, especially on the upperhead when com. pared with pallidiceps from the island of Wetar, which is said to be similar in size. And according to Mayr ${ }^{3}$ sumbanus should be much darker than typical buceroides.

When considering the measurements given below there are indications that the wingsize of birds belonging to buceroides and plesseni indeed averages somewhat smaller than Rensch (loc. cit.) mentions for sumbanus and that we found in the nine males and two females from Sumba among which were eight specimens friendly sent me on loan by Dr. Sutter from Basel, who collected this fine material during his 1948expedition to that island. The subspecies neglectus indeed averages distinctly smaller in wing-and tail-measurements than sumbanus, but pallidiceps may have the same size 
showing, however, a longer bill when looking upon Rensch' figures as given below. With a view on the above there seems reason to maintain sumbanus but because I have not seen sufficient large series of all these races $I$ am not in a position to give a definite conclusion about the validity of this Sumba race.

When comparing the material from Sumba present in the Bogor Museum which has been stored already for about 30 years, with those skins more recently secured by Dr. Sutter, the fresh birds average darker on almost all parts of the plumage.

The two male and two female birds obtained by me on Komodo Island average larger than neglectus known from nearby Flores and they also differ in plumage; they agree in size with sumbanus but they differ from this subspecies in the feathering too: they average much lighter below and the markings on chest, throat and chin show more contrast than is the case in all examined individuals of sumbanus, inclusive the rather fresh birds of Dr. Sutter! Moreover the naked skin on the sides of the head averages larger in extension in Komodo birds than in sumbanus, perhaps similar to representatives of the nominate race. There is also more contrast between the blackish feathers on the sides of the head and the whitish foreneck; also on the upper surface the general impression is quite a different one than in sumbanus, for the colour is greyer, less brown. Two Komodo skins ( $\hat{o}$ o $)$ ) have some ochreous on the throat and one in addition to this some green on the wing-quills but these differences may be of an individual character only.

The colour of the eyes is indicated by Sutter as to be greyish brown, dark chestnut, grey, etc. This may be right in the dead bird but when still alive the colour of the iridis is clear red, which tinge changes at once when the bird dies. This, in any case, was so in the birds living on Komodo Island.

Though there seems some reason to separate Komodo's population of Philemon buceroides I do not think this fully justifiable on account of so little material which, moreover, was preserved in formalin. Also the fact that Prof. Stresemann and Dr. Dean Amadon, who were so kind to compare the Komodo skins with material in Berlin and New York, have the opinion that there is not enough ground to separate those Komodo birds, refrains me from proposing an own name for them. Because of the similarity in size to sumbanus I have included the Komodo material of the species into this race because neglectus from nearby Flores averages considerably smaller in wing-and tail measurements.

Comparison of large series of all existing subspecies, known from the Lesser Sunda Islands may lead to the conclusion that there is not enough reason to uphold so many races.

Measurements (in $\mathrm{mm}$.):

ô of Wing; sumbanus (Sumba, Bogor Museum): 155, 157, 158; sumbanus (Sumba, Sutter collection) : 146, 148, 153, 155, 159, 163 ; sumbanus? (Komodo): 156, 159 ; neglectus 
(Lombok, Sumbawa, Flores): 140, 143, 145, 146; neglectus (Leiden Museum, measured by Junge): 145, 150, 152.

Tail ; sumbanus (Sumba, Bogor Museum) : 135, 140, 143; sumbanus (Sumba, Sutter collection): 132, 136, 137, 140, 143, 143; sumbanus? (Komodo): 135, 138; neglectus (Lombok, etc.): 121, 123, 123, 134; neglectus (Leiden Museum, measured by Junge): $130,130,135$.

Culmen ; sumbanus (Sumba, Bogor Museum): 39.5, 45.3, 46.5; sumbanus (Sumba, Sutter collection): 42.5, 43, 44, 44.5, 46.1, 47 ; sumbanus? (Komodo): 46, 46; neglectus (Lombok, etc.) : 41.2, 42, 43.6, 44, 45; neglectus (Leiden Museum, measured by Junge) : $43.2,44,45.5$.

Max., min. and average measurements :

$\begin{array}{lccccc} & \begin{array}{c}\text { sumbanus } \\ \text { Sumba, Bogor } \\ \text { Museum }\end{array} & \begin{array}{c}\text { sumbanus } \\ \text { Sumba, Sutter } \\ \text { coll. }\end{array} & \begin{array}{c}\text { sumbanus? } \\ \text { Komodo }\end{array} & \begin{array}{c}\text { neglectus } \\ \text { Lombok, etc. }\end{array} & \begin{array}{c}\text { neglectus } \\ \text { Leiden } \\ \text { Museum }\end{array} \\ \text { Wing: } & \frac{155-158}{156.67} & \frac{146-163}{154} & \frac{156-159}{157.50} & \frac{140-146}{143.50} & \frac{145-152}{149} \\ \text { Tail : } & \frac{135-143}{139.33} & \frac{132-143}{138.50} & \frac{135-138}{136.50} & \frac{121-134}{125.25} & \frac{130-135}{131.67} \\ \text { Culmen : } & \frac{39.5-46.5}{43.77} & \frac{42.5-47}{44.52} & \frac{46,46}{46} & \frac{41.2-45}{43.16} & \frac{43.2-45.5}{44.23}\end{array}$

우 우 Wing; sumbanus (Sumba, Bogor Museum): none; sumbanus (Sumba, Sutter collection): 145, 162; sumbanus? (Komodo): 147, 150; neglectus (Lombok, Sumbawa, Flores): 130, 135, 139, 140, 140, 140, 140.

Tail ; sumbanus (Sumba, Sutter collection): 132, 138 ; sumbanus? (Komodo): 127, 136 ; neglectus (Lombok, etc.): 105, 110, 116, 118, 119, 120, 121.

Culmen ; sumbanus (Sumba, Sutter collection): 42, 46; sumbanus? (Komodo): 43, 43 ; neglectus (Lombok, etc.) : 38, 38, 38.8, 38.9, 38.9, 39, 40.7, 41.

Max., min. and average measurements :

$\begin{array}{lccc}\text { Wumba, Sutter coll. } & \begin{array}{c}\text { sumbanus? } \\ \text { Komodo }\end{array} & \begin{array}{c}\text { neglectus } \\ \text { Lombok, etc. }\end{array} \\ \text { Wing: } & \frac{145,162}{153.50} & \frac{147,150}{148.50} & \frac{130-140}{137.71} \\ \text { Tail : } & \frac{132,138}{135} & \frac{127,136}{131.50} & \frac{105-121}{115.57} \\ \text { Culmen : } & \frac{42,46}{44} & \frac{43,43}{43} & \frac{38-41}{39.16}\end{array}$

Some measurements compiled from literature:

Rensch ${ }^{6}$

ㅇํㅇ pallidiceps: Wing 154-158; Culmen : 48-51

plesseni: " 148-156 


$$
\begin{aligned}
& \text { buceroides: " 149-155 } \\
& \text { neglectus: " 144-148 } \\
& \text { Culmen : } \frac{45-46}{45} \text { ? }
\end{aligned}
$$

Mayr $\left.{ }^{3}\right)$

5ో sumbanus: Wing $\frac{156-162}{159} ;$ Tail $: \frac{133-145}{138}$

3 우 sumbanus: " $\frac{146-149}{148} ; \quad " \frac{127-136}{130.67}$

\section{References}

1. Mayr, E. 1941. Über einige Raubvögel der Kleinen Sunda-Inseln; Orn. Monatsb. 49: 44 45.

2. Mayr, E. 1941. List of New Guinea Birds: A systematic and faunal list of the birds of New Guinea and adjacent islands. Amer. Mus. Nat. Hist., New York (p. 103)

3. Mayr, E. 1944. The birds of Timor and Sumba. Bull. Amer. Mus. Nat. Hist. 83: 165.

4. Mees, G.F. 1961. An annotated catalogue of a collection of bird-skins from West Pilbara, Western Australia. J. Roy. Soc. West. Australia $44: 110 \sim 111$.

5. Peters, J. L. 1960. Checklist of birds of the world. 9 (pp. 169 172).

6. Rensch, B. 1931. Uber einige Vogelsammlungen des Buitenzorger Museums von den Kleinen Sunda-Inseln. Treubia 13:385, 400.

7. Rensch, B. 1931. Die Vogelwelt von Lombok, Sumbawa und Flores. Mitteilungen Zool. Mus. Berlin 17: 507 511, 563 564.

8. Stresemann, E. 1924. Raubvogelstudiën: Die Formenkreise Accipiter fasciatus und Accipiter novaehollandiae. J. Orn.: 444 446.

9. Voous, K.H. \& Marle, J.G. van. 1949. The distributional history of Coracina in the IndoAustralian Archipelago. Bijdragen tot de Dierkunde 28: 518 521.

10. Wallace, A. R. 1863. Birds of Timor, Flores and Lombok. Proc. Zool. Soc. London (p. 487) 